\section{$\underset{\substack{\text { hommes } \\ \text { \& migrations }}}{ }$}

\section{Hommes \& migrations}

Revue française de référence sur les dynamiques

migratoires

\section{$1288 \mid 2010$}

Langues et migrations

\title{
Abdelkader Djemaï, Zohra sur la terrasse
}

Paris, Éditions du Seuil 2010, 116 pages, $14 €$

\section{Mustapha Harzoune}

\section{(2) OpenEdition}

1 Journals

\section{Édition électronique}

URL : http://journals.openedition.org/hommesmigrations/902

DOI : 10.4000/hommesmigrations.902

ISSN : 2262-3353

\section{Éditeur}

Musée national de l'histoire de l'immigration

\section{Édition imprimée}

Date de publication : 1 novembre 2010

Pagination : 179

ISSN : 1142-852X

\section{Référence électronique}

Mustapha Harzoune, «Abdelkader Djemaï, Zohra sur la terrasse », Hommes \& migrations [En ligne],

1288 | 2010, mis en ligne le 29 mai 2013, consulté le 22 septembre 2020. URL : http://

journals.openedition.org/hommesmigrations/902; DOI : https://doi.org/10.4000/hommesmigrations. 902

Ce document a été généré automatiquement le 22 septembre 2020.

Tous droits réservés 


\section{Abdelkader Djemaï, Zohra sur la terrasse}

Paris, Éditions du Seuil 2010, 116 pages, $14 €$

Mustapha Harzoune

\section{RÉFÉRENCE}

Abdelkader Djemaï, Zohra sur la terrasse, Paris, Éditions du Seuil 2010, 116 pages, $14 €$

1 Comment un écrivain algérien reçoit les tableaux de Matisse? Ceux que le peintre réalisa au cours de ses deux séjours marocains en 1912, du côté de Tanger ? Citons pour mémoire: Le Rifain, "ce magnifique homme avec des yeux de sauvage" écrira Matisse, Fenêtre ouverte à Tanger, Le Café arabe, Fatmah la mulâtresse, La Casbah de Tanger, ou, bien sûr, Zohra sur la terrasse qui donne le titre de ce livre.

2 Quel regard porte l'enfant du cru sur le regard que l'artiste posa sur "les siens" ? C'est l'intérêt de ce petit livre que de renouveler, à tout le moins de revivifier, la critique des œuvres de Matisse, du moins ceux de ses tableaux nés de sa rencontre avec l'Afrique du Nord, ses populations, ses paysages, ses villes et son art. Un peu comme si le peintre était apprécié par son modèle, l'œuvre par ses personnages, l'artiste français, par son "sujet" nord-africain.

3 Entre quelques incursions dans la biographie du maître, Abdelkader Djemaï laisse remonter à la surface des réminiscences lointaines et ne cache pas sa tendresse pour Matisse. La vie de l'artiste, ses objets, comme bien sûr ses œuvres sont alors le prétexte à quelques convergences. La malle du peintre réveille celle de la mère. Les bains de mer de Matisse rappellent à Abdelkader Djemaï que son grand-père, lui, n'en prenait jamais et que lui-même a bien failli se noyer à 17 ans du côté de Cap Falcon à Oran. Le violon, que Matisse aimait à jouer dans les cafés arabes, rejoint le goût pour la gasba du grandpère. Enfin, et peut-être surtout, Zohra, le modèle, longtemps rétive, qui apparaît sur les toiles du maître, timide, discrète, pudique, remémore à l'esprit d'Abdelkader Djemaï d'autres femmes, des femmes algériennes, des tantes et le souvenir d'un visage, celui 
d'une petite paysanne, âgée alors comme lui de 10 ans, qui s'en allait aux thermes de Hammam Bouhanifia. Il faut dire que c'est Zohra, qui, au hasard d'un livre d'art feuilleté dans une bibliothèque municipale, présenta Henri à Abdelkader. "[...] Coloriste sensible et vigilant, vous essayez d'éviter la théorie, l'exotisme, l'ethnographie et le style trop décoratif ou anecdotique", écrit l'écrivain au peintre.

4 "Rien dans votre œuvre, dans vos propos ou dans votre correspondance ne laisse supposer que votre regard sur ceux qu'on appelait les indigènes fut colonial, condescendant ou folklorique", écrit l'Algérien au Français.

5 "En venant, sans méfiance et sans préjugés, dans ce pays du Maghreb, [...] vous serez alors l'un des premiers à tenter de faire la synthèse entre [l'art musuman] et celui de l'occident, offrant ainsi à l'art moderne un espace plus vaste et plus riche dans ses formes et dans ses contenus", écrit celui qui inscrit sans doute une part de son œuvre dans le sillon creusé par l'artiste. Cet "espace, plus vaste et plus riche" ne rejoint-t-il pas celui, que constituent, aujourd'hui, nombre d'auteurs à cheval sur plusieurs continents, plusieurs pays, plusieurs cultures et plusieurs langues? Comme Abdelkader Djemaï qui appartient à ce que Matisse appelait "la grande famille humaine" et pour qui il voulut "révéler un peu de la fraîche beauté du monde..." 